\title{
Ring-Opening Polymerisation of Low-Strain Nickelocenophanes: Synthesis and Magnetic Properties of Polynickelocenes with Carbon
}

\section{and Silicon Main Chain Spacers}

Rebekah L. N. Hailes, ${ }^{\dagger}$ Rebecca A. Musgrave, ${ }^{\dagger}$ Alexander F. R. Kilpatrick, ${ }^{\dagger}$ Andrew D. Russell, ${ }^{\dagger}$ George R. Whittell, ${ }^{\dagger}$ Dermot O’Hare, ${ }^{* \dagger}$ and Ian Manners ${ }^{* \dagger}{ }^{\dagger}$

${ }^{\dagger}$ School of Chemistry, University of Bristol, Bristol BS8 1TS, United Kingdom

\#Department of Chemistry, University of Victoria, Victoria, BC V8W 3V6, Canada

ॠChemistry Research Laboratory, Department of Chemistry, University of Oxford, Oxford OX1 3TA, United Kingdom

*e-mail: dermot.ohare@chem.ox.ac.uk, ian.manners@bristol.ac.uk

\begin{abstract}
Polymetallocenes based on ferrocene, and to a lesser extent cobaltocene, have been wellstudied, whereas analogous systems based on nickelocene are virtually unexplored. We have previously shown that poly(nickelocenylpropylene) $\left[\mathrm{Ni}\left(\eta^{5}-\mathrm{C}_{5} \mathrm{H}_{4}\right)_{2}\left(\mathrm{CH}_{2}\right)_{3}\right]_{\mathrm{n}}$ is formed as a mixture of cyclic $\left(\mathbf{6}_{\mathbf{x}}\right)$ and linear (7) components by the ring-opening polymerisation (ROP) of tricarba[3]nickelocenophane $\left[\mathrm{Ni}\left(\eta^{5}-\mathrm{C}_{5} \mathrm{H}_{4}\right)_{2}\left(\mathrm{CH}_{2}\right)_{3}\right](\mathbf{5})$. Herein we demonstrate the generality of this approach to main-chain polynickelocenes and describe the ROP of tricarba[4]nickelocenophane $\left[\mathrm{Ni}\left(\eta^{5}-\mathrm{C}_{5} \mathrm{H}_{4}\right)_{2}\left(\mathrm{CH}_{2}\right)_{4}\right](\mathbf{8})$, and disila[2]nickelocenophane $\left[\mathrm{Ni}\left(\eta^{5}\right.\right.$ $\left.\left.\mathrm{C}_{5} \mathrm{H}_{4}\right)_{2}\left(\mathrm{SiMe}_{2}\right)_{2}\right] \quad$ (12) to yield predominantly insoluble homopolymers poly(nickelocenylbutylene) $\left[\mathrm{Ni}\left(\eta^{5}-\mathrm{C}_{5} \mathrm{H}_{4}\right)_{2}\left(\mathrm{CH}_{2}\right)_{4}\right]_{\mathrm{n}}$ and poly(tetramethyldisilylnickelocene) $\left[\mathrm{Ni}\left(\eta^{5}-\mathrm{C}_{5} \mathrm{H}_{4}\right)_{2}\left(\mathrm{SiMe}_{2}\right)_{2}\right]_{\mathrm{n}}(\mathbf{1 4})$, respectively. The former
\end{abstract}


represents the first example of $[n]$ metallocenophane ROP in the absence of $\mathrm{Cp}$ ring tilt. Additionally, the ROP of $\mathbf{8}$ and $\mathbf{1 2}$ were found to be reversible at elevated temperature. To access soluble high molar mass materials, copolymerisations of $\mathbf{5}, \mathbf{8}$, and $\mathbf{1 2}$ were performed. SQUID magnetometry measurements of $\mathbf{1 3}$ and $\mathbf{1 4}$ indicated that these homopolymers behave as simple paramagnets at temperatures greater than $50 \mathrm{~K}$, with significant antiferromagnetic coupling that is notably larger in carbon-bridged $\mathbf{6} \mathbf{x} / 7$ and $13 \mathbf{a}$ compared to the disilyl-bridged 14a. However, the behaviour of these polynickelocenes deviates substantially from the CurieWeiss law at low temperatures due to considerable zero-field splitting.

\section{Introduction}

Metal-containing polymers (metallopolymers), in which the inherent functionality of metal centres is combined with the facile processing typical of organic polymers, have long been regarded as a desirable target. ${ }^{1-3}$ The diverse structure and properties which result as a function of metal incorporation have proved crucial in a variety of applications including catalysis, ${ }^{4}$ antibacterial activity, ${ }^{5}$ photovoltaics, ${ }^{6-7}$ information storage,${ }^{8}$ light emission,,${ }^{9-10}$ self-healing,,${ }^{11-}$ 12 stimuli-responsive behaviour, ${ }^{13}$ ceramic formation, ${ }^{14-17}$ and nanopatterning. ${ }^{18-20}$ Although the metallopolymer field has been subject to considerable recent progress, there have been few reports of well-characterised nickel-based polymers. Examples include $\pi$-conjugated nickelpolyyne copolymers, ${ }^{21}$ metallophthalocyanine covalent organic frameworks, ${ }^{22}$ bis(phosphine)nickel(II)-1,4-tetrafluorophenylene polymers, ${ }^{23-25}$ polymers featuring nickel(II) complexes of Goedken's macrocycle (4,11-dihydro-5,7,12,14tetramethyldibenzo[b,i] $[1,4,8,11]$ tetraazacyclotetradecine $),{ }^{26}$ and those included in Figure $1 .{ }^{27-}$ 32 


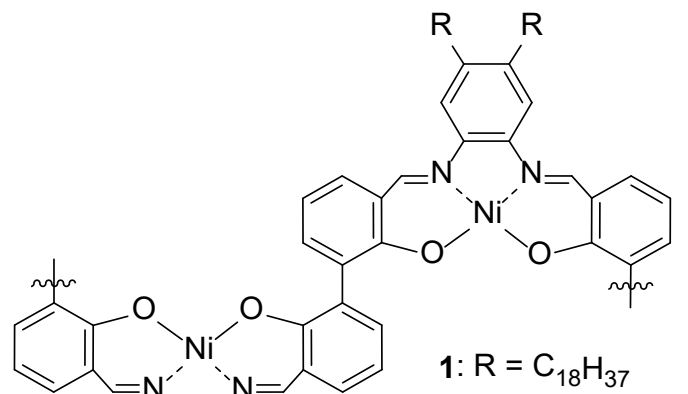

$=\gamma_{R}$

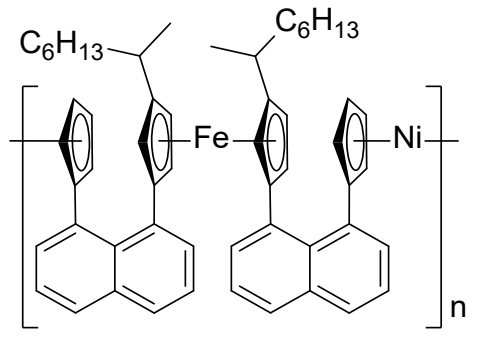

2

4

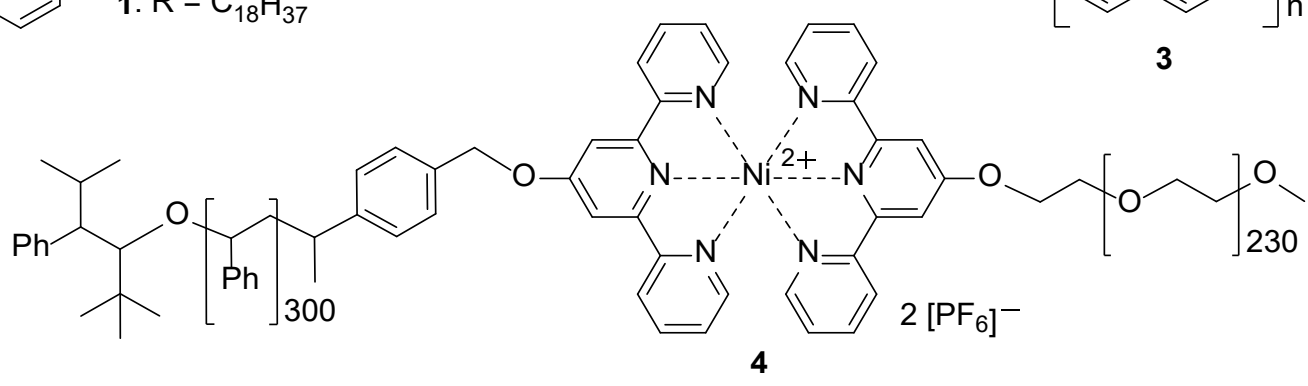

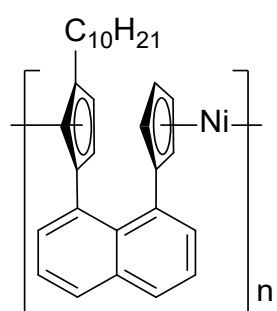

3

Figure 1. Examples of nickel-containing polymers.

ROP of strained $[n]$ metallocenophanes has attracted extensive attention as a pathway to well defined metal-containing polymers and block copolymers. ${ }^{33-36}$ In particular, polyferrocenylsilanes, prepared by the ROP of 18 valence electron (VE) silicon-bridged [1]ferrocenophanes, have been studied in depth and have thus attracted interest as redox active films, capsules, and gels, ${ }^{37-39}$ precursors to catalytically active and magnetic ceramics, ${ }^{40-41}$ plasma and electron beach etch resists, ${ }^{19,}{ }^{42}$ and self-assembled materials with controlled lengths and architectures. ${ }^{33,43-44}$ As a result of the 20 valence electron configuration of nickelocene, two electrons are accommodated in antibonding $\mathrm{e}^{\prime \prime}{ }_{1}$ orbitals, resulting in the elongation and weakening of the nickel-cyclopentadienyl (Ni-Cp) bond ${ }^{45}$ and a subsequent increase in the $\mathrm{Cp}$ ligand tilt-angle, $\alpha$, comparative to iron and cobalt metallocene analogues. ${ }^{46-}$ 48 This weaker M-Cp bond is reflected in the low number of reported $[n]$ nickelocenophane structures compared to well-studied $[n]$ ferrocenophanes; currently reported species are limited to those bridged with unsubstituted alkylene chains where $n$ is greater than 2 , namely $\mathbf{5},{ }^{49} \mathbf{8}$ $\mathbf{1 0},{ }^{49}$ naphthalene, 11, ${ }^{50}$ and disila linkers, $\mathbf{1 2},{ }^{48}$ (Figure 2). 


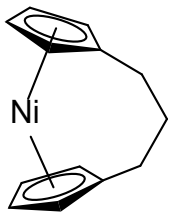

5

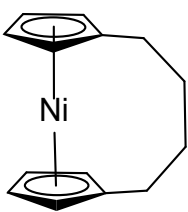

8

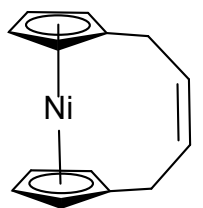

9

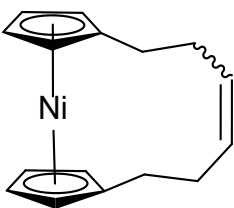

10

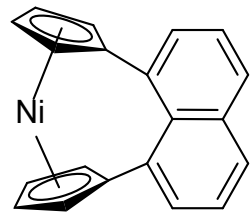

11

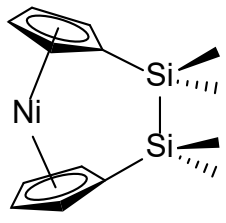

12

Figure 2. Currently structurally characterised $[n]$ nickelocenophanes.

Currently, the only reported high molar mass polynickelocene, poly(nickelocenylpropylene) 7, results from the ROP of tricarba[3]nickelocenophane $5[\alpha=$ $\left.16.6(1)^{\circ}\right]$ in pyridine (and a number of other polar organic solvents), Scheme $1 .{ }^{49,51}$ It was also demonstrated that, as a consequence of the weak $\mathrm{Ni}-\mathrm{Cp}$ bonds $(\mathrm{M}-\mathrm{Cp}$ dissociation energy is $250 \mathrm{~kJ} \mathrm{~mol}^{-1}$ for nickelocene vs. $305 \mathrm{~kJ} \mathrm{~mol}^{-1}$ for ferrocene), ${ }^{52}$ the polynickelocene $7 \mathrm{can}$ exist in either a static or labile state depending on the solvent conditions and, in the latter case, forms a dynamic equilibrium with monomer 5 and oligomers $6 \mathbf{x} / 7$ (Scheme 1). ${ }^{51}$ Studies of the equilibrium between monomer 5 and polymer $6 \mathrm{x} / 7$ allowed for the determination of enthalpic and entropic parameters that characterise this ROP process, revealing a small, favourable value of $\Delta \mathrm{H}\left(-10 \mathrm{~kJ} \mathrm{~mol}^{-1}\right)$, and a very small and unfavourable value of $\Delta \mathrm{S}\left(-21 \mathrm{~J} \mathrm{~K}^{-1} \mathrm{~mol}^{-1}\right) .^{51}$
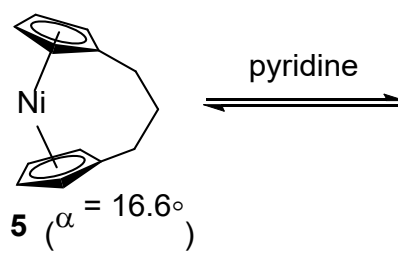

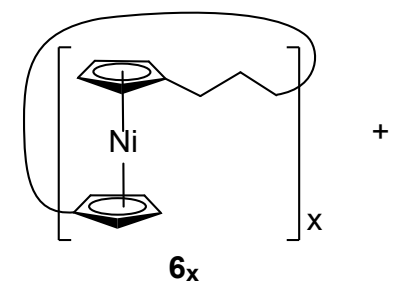

Scheme 1

Scheme 1. Reversible ROP of tricarba[3]nickelocenophane 5.

The polymerisation of $\mathbf{5}$ is believed to proceed via initial coordination of pyridine to the nickel centre and subsequent cleavage of the $\mathrm{Ni}-\mathrm{Cp}$ bond, ${ }^{51}$ a similar mechanism to that of the photolytic ROP of sila[1]ferrocenophanes, ${ }^{53}$ although photoexcitation of the nickel-based 
monomer is unnecessary in this case, presumably due to the inherent lability of the $\mathrm{Ni}-\mathrm{Cp}$ bond. Analysis of the resulting poly(nickelocenepropylene) by MALDI-TOF mass spectrometry revealed the presence of both cyclic and linear polymeric species, the former of which suggests that the pyridine initiator is substitutionally labile when coordinated at a $\left[\mathrm{C}_{5} \mathrm{H}_{4} \mathrm{R}\right] \mathrm{Ni}$ centre, which may therefore allow for easy displacement by the propagating anionic Cp end group. ${ }^{49}$

SQUID magnetometry was used to determine the solid-state magnetic properties of poly(nickelocenepropylene) $7 .{ }^{49}$ Above $28 \mathrm{~K}$, polynickelocene 7 was found to behave as a simple paramagnet, and the magnetic susceptibility per monomer unit could be fitted to the Curie-Weiss law (with a small additional term for temperature-independent paramagnetic contribution). In addition, a large, negative Weiss constant suggested significant antiferromagnetic spin-spin interactions. The magnetic susceptibility for 7 deviated from that expected of a simple paramagnet below $28 \mathrm{~K}$; however, the exact nature of the spin-spin interactions was not determined. ${ }^{49}$

Herein we report the synthesis of two novel polynickelocenes via ROP of low-strain nickelocenophanes, and a subsequent investigation of the ability of the parent $[n]$ nickelocenophanes to copolymerise. Due to the presence of two unpaired electrons on every main-chain centre in polynickelocenes, the magnetic properties of the homopolymers were explored in detail using SQUID magnetometry.

\section{Results and Discussion}

\section{Synthesis and ROP of Tetracarba[4]nickelocenophane (8)}

In the case of the ROP of $\mathbf{5}, \Delta \mathrm{H}_{\mathrm{ROP}}$ is small and negative, because the polymerisation is driven by the (albeit small) release of ring strain. ${ }^{51}$ To provide an interesting comparison we explored the polymerisation of tetracarba[4]nickelocenophane 8. This species has previously been 
prepared via the ring-closing metathesis of a divinyl substituted nickelocene followed by a subsequent hydrogenation. ${ }^{54}$ In our work the synthesis of $\mathbf{8}$ was conducted via an analogous fly trap synthesis to that employed for the tricarba analogue 5, involving the reaction of the dilithiated ligand $\mathrm{Li}_{2}\left[\left(\mathrm{C}_{5} \mathrm{H}_{4}\right)_{2}\left(\mathrm{CH}_{2}\right)_{4}\right]$ and $\mathrm{NiCl}_{2}$ (see Supporting Information). This gave 8 as a crystalline green solid in very low yield. Paramagnetic ${ }^{1} \mathrm{H}$ NMR spectroscopy revealed $\alpha$ and $\beta$ cyclopentadienyl resonances at -251.2 and $-256.6 \mathrm{ppm}$ respectively, an $\alpha-\mathrm{CH}_{2}$ resonance at $138.2 \mathrm{ppm}$, and a $\beta-\mathrm{CH}_{2}$ resonance at $-1.1 \mathrm{ppm}$ (Figure $\mathrm{S} 1$ ). These signals in the ${ }^{1} \mathrm{H}$ NMR spectrum are consistent with those previously reported. ${ }^{54}$ Although the crystallographic data in the original report were not provided in full due to poor refinement, we isolated dark green crystals which allowed for full characterisation by single crystal X-ray diffraction (Figure 3).
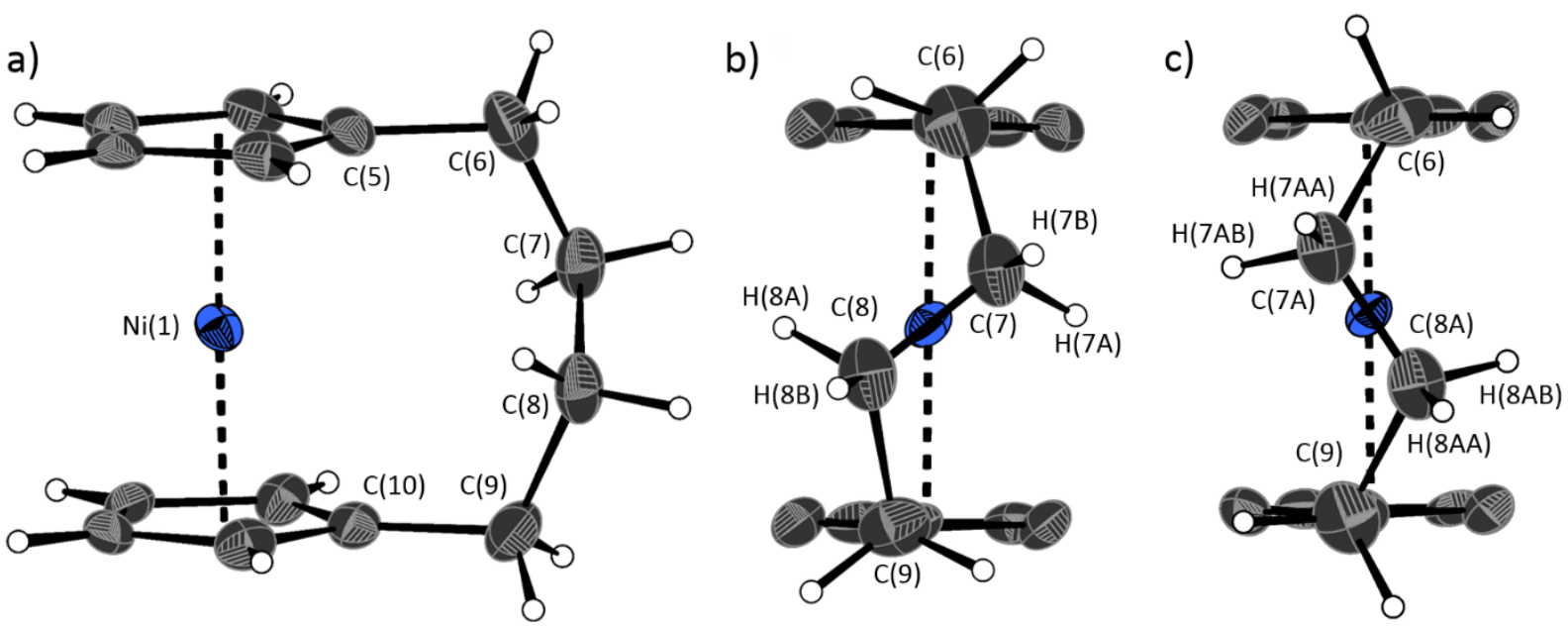

Figure 3. a) Molecular structure of 8 . Thermal ellipsoids displayed at the $50 \%$ probability level. Hydrogen atoms are pictured as spheres of arbitrary radii (and some have been omitted for clarity). The ansa bridge is disordered over two positions: C7/7A and C8/8A (for clarity, positions with highest relative occupancy (62\%) are displayed). Alternate view of $\mathbf{8}$ displaying b) major (62\%) and c) minor (38\%) component of disordered bridge. Selected distances $(\AA)$ and angles $\left({ }^{\circ}\right)$ : $\mathrm{Ni}(1)-\mathrm{Cp}_{\text {cent }} 1.813(3) / 1.817(3), \alpha=1.0(3), \delta=178.63(11)$ (the angle $\delta$ is defined as the $\mathrm{Cp}^{\mathrm{C}}-\mathrm{Ni}-\mathrm{Cp}^{\mathrm{C}}\left(\mathrm{Cp}^{\mathrm{C}}=\mathrm{Cp}\right.$ centroid $)$ angle $)$.

As expected, species 8 does not exhibit significant $\mathrm{Cp}$ ring tilt $\left(\alpha=1.0(3)^{\circ} ; \delta=178.63(11)^{\circ}\right)$. 
This lack of ring strain in $\mathbf{8}$ relative to the case of $\mathbf{5}$ led to the expectation that $\mathbf{8}$ would be resistant to ROP as, in general, the thermodynamic driving force for the ROP of $[n]$ metallocenophanes is attributed to the strain imposed by ansa-bridging moieties in the cyclic monomers. ${ }^{55-58}$ In order to probe the ROP propensity of $\mathbf{8}$ this species was exposed to similar ROP conditions to those successfully used for monomer 5 (pyridine, $0.74 \mathrm{M}, 5$ days, $20{ }^{\circ} \mathrm{C}$, Scheme 2). Although the green solution that was obtained upon dissolution of monomer 8 did not noticeably change colour, a light green solid (13a) precipitated from solution, which was found to be insoluble in common organic solvents such as THF, dichloromethane, and benzene.

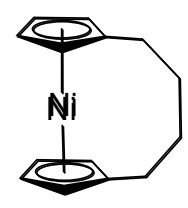

8

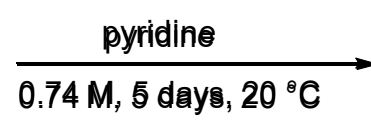

Scheme 2. ROP of 11 in pyridine $(0.74 \mathrm{M})$.

The remaining solution was found to contain a small amount of oligomeric material $(\mathbf{1 3} \mathbf{b})$, which failed to precipitate upon addition of this solution to $n$-hexanes. Analysis by MALDITOF mass spectrometry led to the detection of oligomeric species up to $n=10$ repeat units, with the presence of both linear and cyclic species (Figure 4). In addition, ${ }^{1} \mathrm{H}$ NMR spectroscopic analysis of the solution showed the presence of both the starting monomer $\mathbf{8}$ and new resonances at 225.9, between 176.3 and 194.9, and at $-252.6 \mathrm{ppm}$, assigned to oligo(nickelocenylbutylene) 13b (Figure S2). 


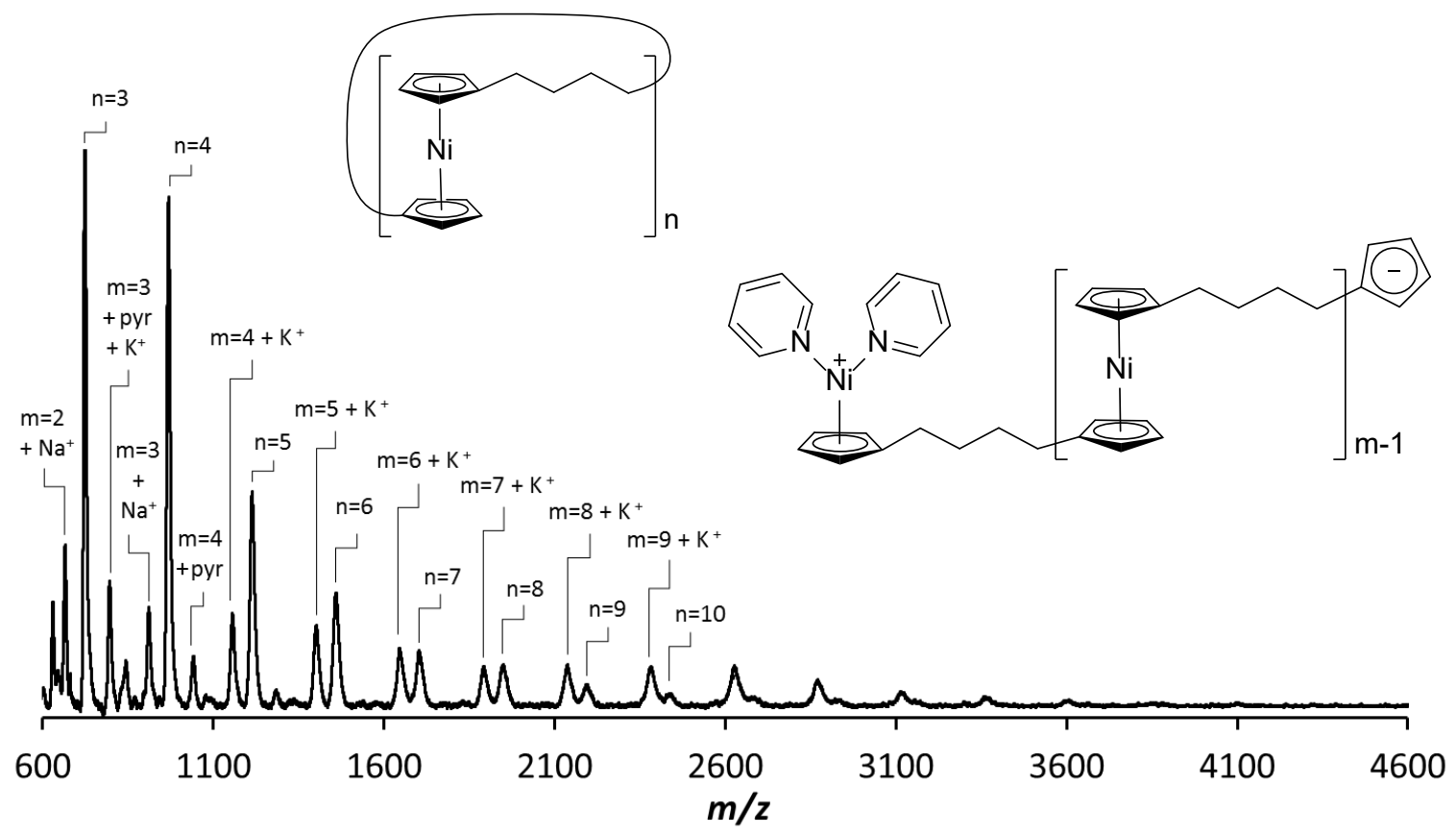

Figure 4. MALDI-TOF mass spectrum of the soluble, oligomeric product $\mathbf{1 3}_{\mathbf{b}}$. Pyridine is represented by pyr, and sodium and potassium by their atomic symbols.

Wide angle X-ray scattering (WAXS) analysis of the insoluble component $\left(\mathbf{1 3}_{\mathbf{a}}\right)$ led to the detection of crystalline reflections at 5.897, 5.333, 5.040, 4.728, 3.644 and $2.945 \AA$ (Figure S3). We have tentatively assigned the structure of this insoluble component 13a to higher molecular weight poly(nickelocenylbutylene) $\left(\mathrm{DP}_{\mathrm{n}}>10\right)$. It appears that the polynickelocene becomes increasingly insoluble as the molecular weight of the polymer increases, which may at least partly be a consequence of the crystallinity. We previously reported that THF-soluble 6x/7 displayed crystalline reflections in the WAXS analysis. As a result of the linear $-\left(\mathrm{CH}_{2}\right)_{4}-$ linkers, 13a appears to mirror linear polyethylene which lacks solubility in common organic solvents due to crystallinity and the lack of solubilising flexible side groups.

Low concentrations and increased temperatures were found to favour $[n]$ nickelocenophane formation in the depolymerisation of $6 \mathbf{x} / 7 .^{51}$ To study whether an analogous depolymerisation of $\mathbf{1 3} \mathbf{a}$ would occur, it was submitted to stirring in $d_{5}$-pyridine at 
low concentration $\left(0.11 \mathrm{M}, 20^{\circ} \mathrm{C}\right)$ for 1 week; however, no paramagnetic resonances were observed by ${ }^{1} \mathrm{H}$ NMR spectroscopy suggesting that there was no retroconversion to monomer. This is a possible consequence of the insolubility of $\mathbf{1 3} \mathbf{a}$ at room temperature. The suspension of 13a was then heated for $24 \mathrm{~h}$ at a range of different temperatures, from 30 to $80{ }^{\circ} \mathrm{C}$, and analysed by in situ ${ }^{1} \mathrm{H}$ NMR spectroscopy (Figure 5). The results indicated that below $50{ }^{\circ} \mathrm{C}$ 13a is essentially insoluble in pyridine. However, at $50{ }^{\circ} \mathrm{C}$ emergences of resonances attributed to both $\mathbf{8}$ and $\mathbf{1 3}$ were detected, which suggests that a similar dynamic equilibrium exists to the case of 5 and $\mathbf{6}_{\mathbf{x}} / 7$. This is only apparent at higher temperatures, presumably as heating is necessary to solubilise $\mathbf{1 3}$ a. Temperature also affects the position of equilibrium, with monomer favoured at high temperatures as in the case of $\mathbf{5}$ and $\mathbf{6}_{\mathbf{x}} / 7^{51}$

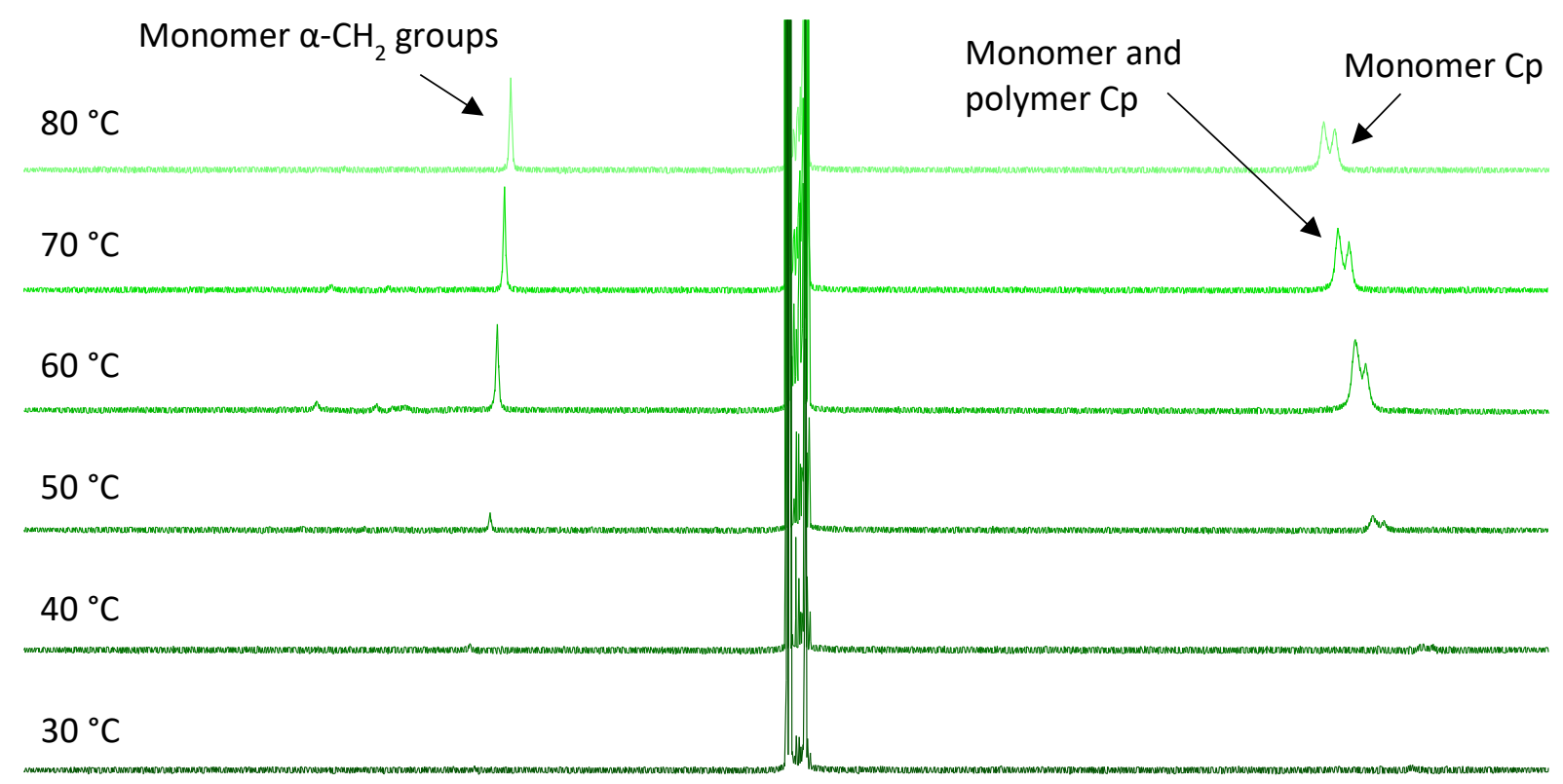

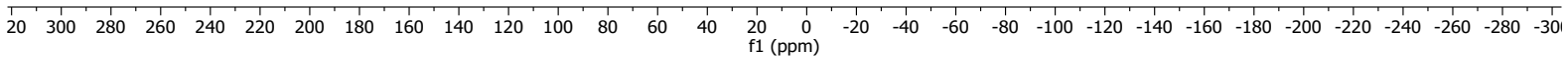

Figure 5. Stacked ${ }^{1} \mathrm{H}$ NMR spectra $\left(500 \mathrm{MHz}, d_{5}\right.$-pyridine) that show the effect of temperature on the retroconversion of polymer 13a into monomer 8 .

ROP of Tetramethyldisila[2]nickelocenophane (12) 
Disila[2]nickelocenophane 12, which has been previously reported by Braunschweig and coworkers, ${ }^{48}$ was synthesised as previously described via lithiation of the 'fly trap' ligand and subsequent reaction with $\mathrm{NiCl}_{2}$ to give a green crystalline solid. Species 12 possesses a tiltangle of $9.37(8)^{\circ}$, an intermediate value between the tilt-angles of $\mathbf{5}$ and $\mathbf{8}\left(\alpha=16.6^{\circ}\right.$ and $1.0^{\circ}$ respectively). Monomer 12 was also subjected to the successful ROP conditions found for $\mathbf{8}$ (pyridine, $0.35 \mathrm{M}, 32 \mathrm{~h}, 20{ }^{\circ} \mathrm{C}$ ) to probe its propensity to polymerise. In a similar manner to the ROP of $\mathbf{8}$, a light green solid (14a) precipitated from solution, which was found to be insoluble in common organic solvents such as THF, dichloromethane, and benzene (Scheme 3).
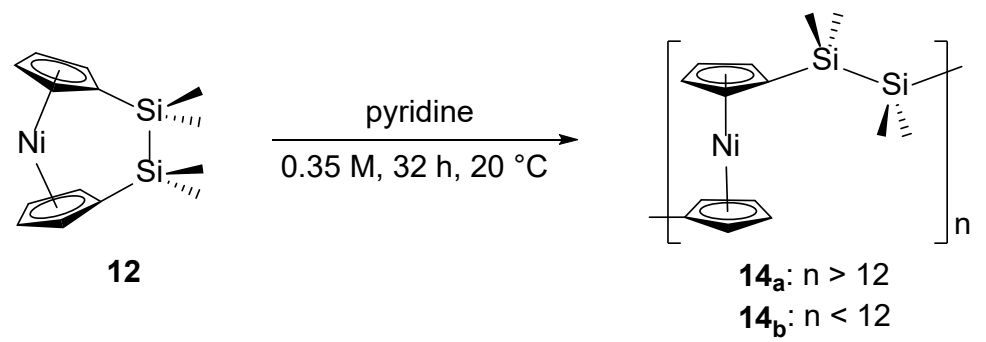

Scheme 3. ROP of disila[2]nickelocenophane $\mathbf{1 2}$ in pyridine.

A small portion of the product (5\%) was found to be soluble in THF, and upon transfer into $n$ hexanes, precipitation of light green material (14b) was observed. ${ }^{1} \mathrm{H}$ NMR spectroscopy of $\mathbf{1 4} \mathbf{b}$ revealed Cp resonances at -243 and $-229 \mathrm{ppm}$ (Figure $\mathrm{S} 4$ ), and $\mathrm{SiMe}_{2}$ resonances at $15.3 \mathrm{ppm}$. MALDI-TOF analysis revealed the presence of oligomers $\left(\mathrm{DP}_{\mathrm{n}}<12\right)$ assigned to two linear modes (Figure 6). 


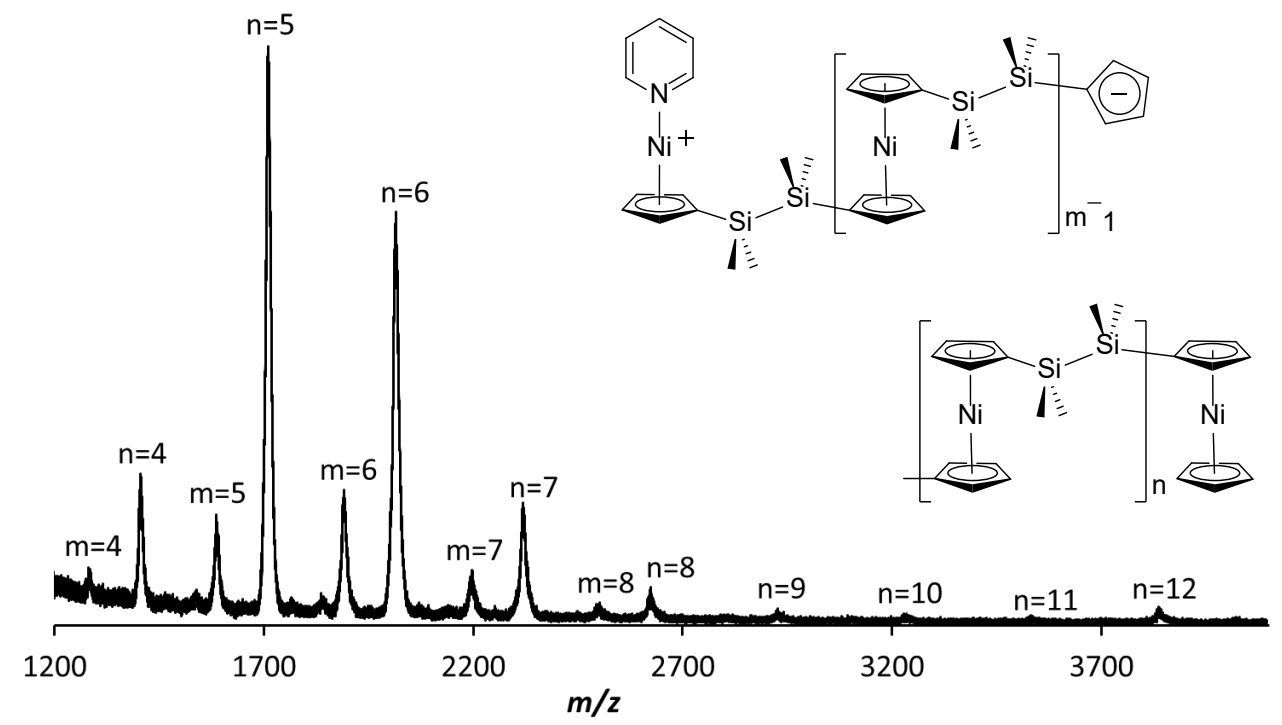

Figure 6. MALDI-TOF mass spectrum of oligo(tetramethyldisilylnickelocene) $\mathbf{1 4} \mathbf{b}$.

The insoluble polymeric material $\mathbf{1 4}$ a is likely to be a high molecular weight $\left(\mathrm{DP}_{\mathrm{n}}>12\right)$ fraction of poly(tetramethyldisilylnickelocene), which is analogous to the case of $\mathbf{1 3} \mathbf{a}$ formed during the ROP of $\mathbf{8}$. Crystallinity may again contribute to the insolubility as WAXS analysis of 14a showed reflections at 8.988, 6.235, 5.882, 4.549 and $3.698 \AA$ (Figure S5).

In a similar manner to poly(nickelocenylbutylene) 13, when reintroduced to (deuterated) pyridine at room temperature and low concentration $(0.11 \mathrm{M})$, no depolymerisation of $\mathbf{1 4}$ a occurred, as evidenced by a lack of monomer signals in the ${ }^{1} \mathrm{H}$ NMR spectrum. The insoluble polymer $\mathbf{1 4}$ a was then equilibrated in $d_{5}$-pyridine at low concentration $(0.11 \mathrm{M})$ for $24 \mathrm{~h}$ at a range of different temperatures, from 30 to $80{ }^{\circ} \mathrm{C}$, and analysed by in situ ${ }^{1} \mathrm{H}$ NMR spectroscopy (Figure S6). At temperatures up to $50{ }^{\circ} \mathrm{C}$ an increase in the intensity of resonances attributed to $\mathbf{1 2}$ could be observed. At $50{ }^{\circ} \mathrm{C}$ a small shoulder resonance attributed to polymer can also be observed in the paramagnetic region. This clearly demonstrates the retroconverion of $\mathbf{1 4}$ to give $\mathbf{1 2}$. Above $50{ }^{\circ} \mathrm{C}$ however, $\mathrm{Cp}$ resonances decrease in intensity alongside the emergence of new unassigned resonances in the diamagnetic region, suggesting the onset of decomposition of the nickelocene-based species. 


\section{Copolymerisation Experiments}

In general, although there are some reported examples of copolymers containing nickelocene units in the main chain, ${ }^{29-30,59}$ they are far less common than their iron and cobalt analogues. In order to circumvent the insolubility of homopolymers $\mathbf{1 3} \mathbf{a}$ and $\mathbf{1 4} \mathbf{a}$ with $\mathrm{C}_{4}$ and disilyl linkers, respectively, we explored random copolymerisation of the respective monomers. This was expected to reduce the crystallinity of the resulting materials by incorporating repeat units derived from a different $[n]$ nickelocenophane, and to thereby promote solubility.

\section{i. Random copolymerisation of 5 and 12}

A copolymerisation of equimolar amounts of tricarba-bridged $\mathbf{5}$ and disilyl-bridged $\mathbf{1 2}$ was conducted (pyridine, $0.08 \mathrm{M}, 32 \mathrm{~h}, 20{ }^{\circ} \mathrm{C}$, Scheme 4). The pyridine was removed, and precipitation of the resulting material from THF into a vortex of $n$-hexanes allowed the isolation of copolymer $\mathbf{1 5}$ as a light green powder in $39 \%$ yield.

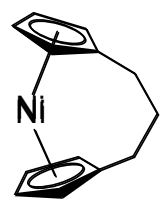

5

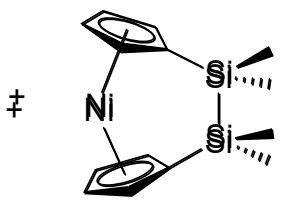

12
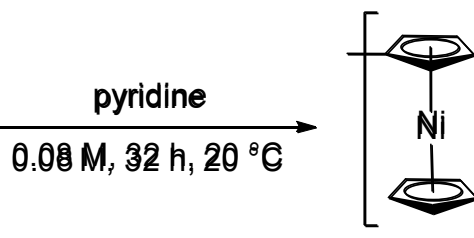

Scheme 4. Co-ROP of $[n]$ nickelocenophanes 5 and 12.

${ }^{1} \mathrm{H}$ NMR spectroscopy in $d_{6}$-benzene revealed eight broad resonances which were assigned to the $\mathrm{Cp}$ environments (ranging from -272 to -228 ppm: see Figure S9). Resonances at 15.3, 10.2 and between 173-176 ppm were assigned to $\mathrm{SiMe}_{2}$ groups, and the $\beta-\mathrm{CH}_{2}$ and $\alpha-\mathrm{CH}_{2}$ protons of the propyl linker respectively, indicating that the polymer $\mathbf{1 5}$ contained repeat units derived from both monomers 5 and 12. These assignments were made based on the resonances of homopolymers $\mathbf{6} \mathbf{x} / \mathbf{7}$ and $\mathbf{1 4} b$ in their respective spectra. The hexanes soluble supernatant 
contained peaks corresponding to both $[n]$ nickelocenophane monomers and low molecular weight co-oligomers.

Further evidence for copolymerisation was provided by MALDI-TOF mass spectrometry (Figure 7), which revealed the presence of low molecular weight linear and cyclic polymer material $\left(<3,000 \mathrm{~g} \mathrm{~mol}^{-1}\right)$, assigned to combinations of repeat units derived from both 5 and 12 (in addition to cyclic homopolymer derived solely from 5). The proposed mechanism for polymerisation of $\mathbf{5}$ in donor solvents involves cleavage of the $\mathrm{Ni}-\mathrm{Cp}$ bond to give a $14 \mathrm{VE}$ nickel cation, and subsequent coordination of solvent, with polymer formation by either a chain-growth or step-growth mechanism (or a combination of both). ${ }^{51}$ The formation of copolymer 15 suggests that both $[n]$ nickelocenophanes 5 and $\mathbf{1 2}$ polymerise via a similar NiCp bond cleavage pathway. DLS measurements on copolymer $15\left(R_{\mathrm{h}}=3.9 \mathrm{~nm}\right.$, Figure S10) indicated a molecular weight, $M_{\mathrm{w}}$, of ca. $25,000 \mathrm{~g} \mathrm{~mol}^{-1}$ and $\mathrm{DP}_{\mathrm{n}}$ of ca. 95 (relative to calibration with poly(ferrocenyldimethylsilane) in THF) ${ }^{60-61}$ which, alongside evidence from MALDI-TOF mass spectrometry, demonstrates the inclusion of monomer units derived from 12 into a high molecular weight soluble polymer. 


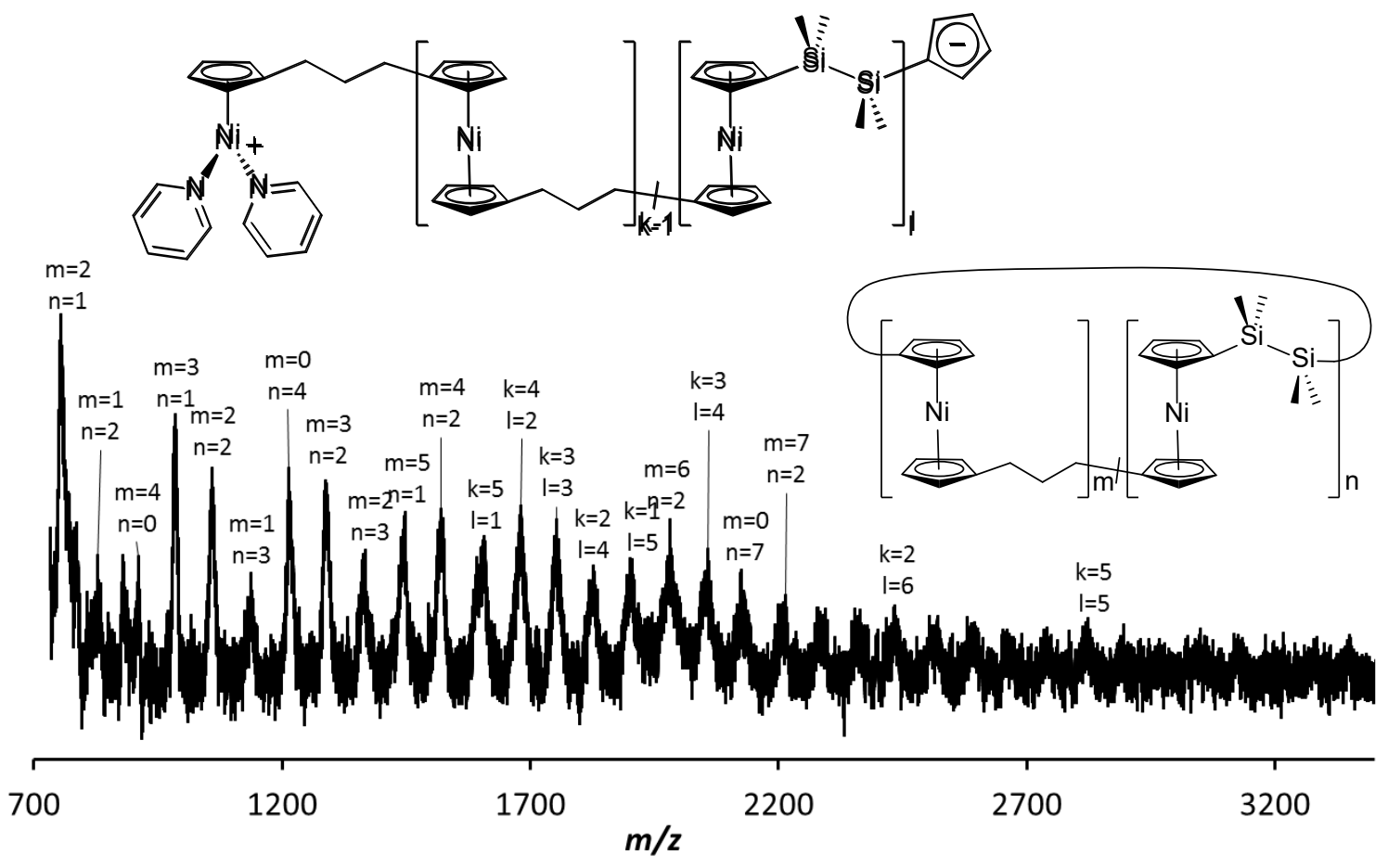

Figure 7. MALDI-TOF mass spectrum of copolymer 15.

\section{ii. Random copolymerisation of 8 and 12}

The potential copolymerisation of tetracarba-derived $\mathbf{8}$ with disilyl-bridged $\mathbf{1 2}$, which both polymerise spontaneously in pyridine to give largely insoluble products 13 a and 14 a, was also studied (Scheme 5). Precipitation of light green material (16a) was observed during the course of the reaction, and this solid was found to be insoluble in organic solvents. However, a soluble polymeric fraction $\mathbf{1 6} \mathbf{b}$ was also isolated in $15 \%$ yield after precipitation into $n$-hexanes. It is interesting to note that the yield of isolable soluble copolymeric material is only slightly increased relative to the two independent homopolymerisations of monomers 8 and $\mathbf{1 2}$ (ca. 5\% in each case). 


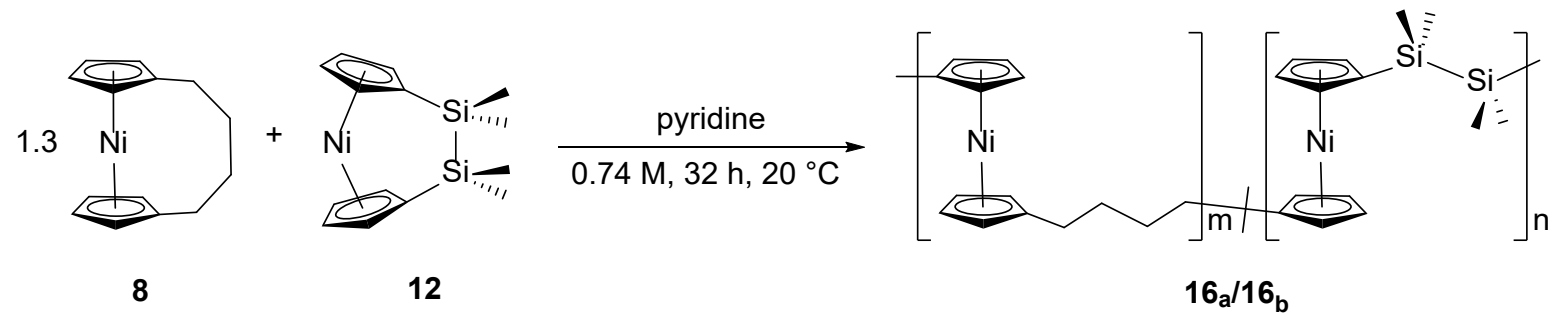

Scheme 5. Co-ROP of $[n]$ nickelocenophanes 8 and $\mathbf{1 2}$.

${ }^{1} \mathrm{H}$ NMR spectroscopy of $\mathbf{1 6} \mathbf{b}$ indicated formation of a new polymeric product, with resonances ranging from -258 to $-236 \mathrm{ppm}$ (see Figure S11) corresponding to $\mathrm{Cp}$ environments. The resonance at $15.2 \mathrm{ppm}$ was assigned to $\mathrm{SiMe}_{2}$ groups, and that at $176 \mathrm{ppm}$ to the $\mathrm{C}_{4}$ linker. MALDI-TOF MS (Figure 8) of the polymeric product detected cyclic oligomeric copolymeric species of up to 22 repeat units (incorporating monomer units derived from both $\mathbf{8}$ and 12). DLS indicated the presence of a macromolecular species $\left(R_{\mathrm{h}}=1.4 \mathrm{~nm}\right.$, Figure $\left.\mathrm{S} 12\right)$ of $M_{\mathrm{w}}=$ ca. $3,800 \mathrm{~g} \mathrm{~mol}^{-1}$ and $\mathrm{DP}_{\mathrm{n}}=$ ca. 14 (relative to calibration with poly(ferrocenyldimethylsilane) in THF) ${ }^{61-62}$ WAXS analysis of the insoluble component 16a was very similar to that of disilylbridged homopolymer 14a, with reflections detected at 6.177, 5.739, 3.634 and 2.367 $\AA$ (Figure S13). 


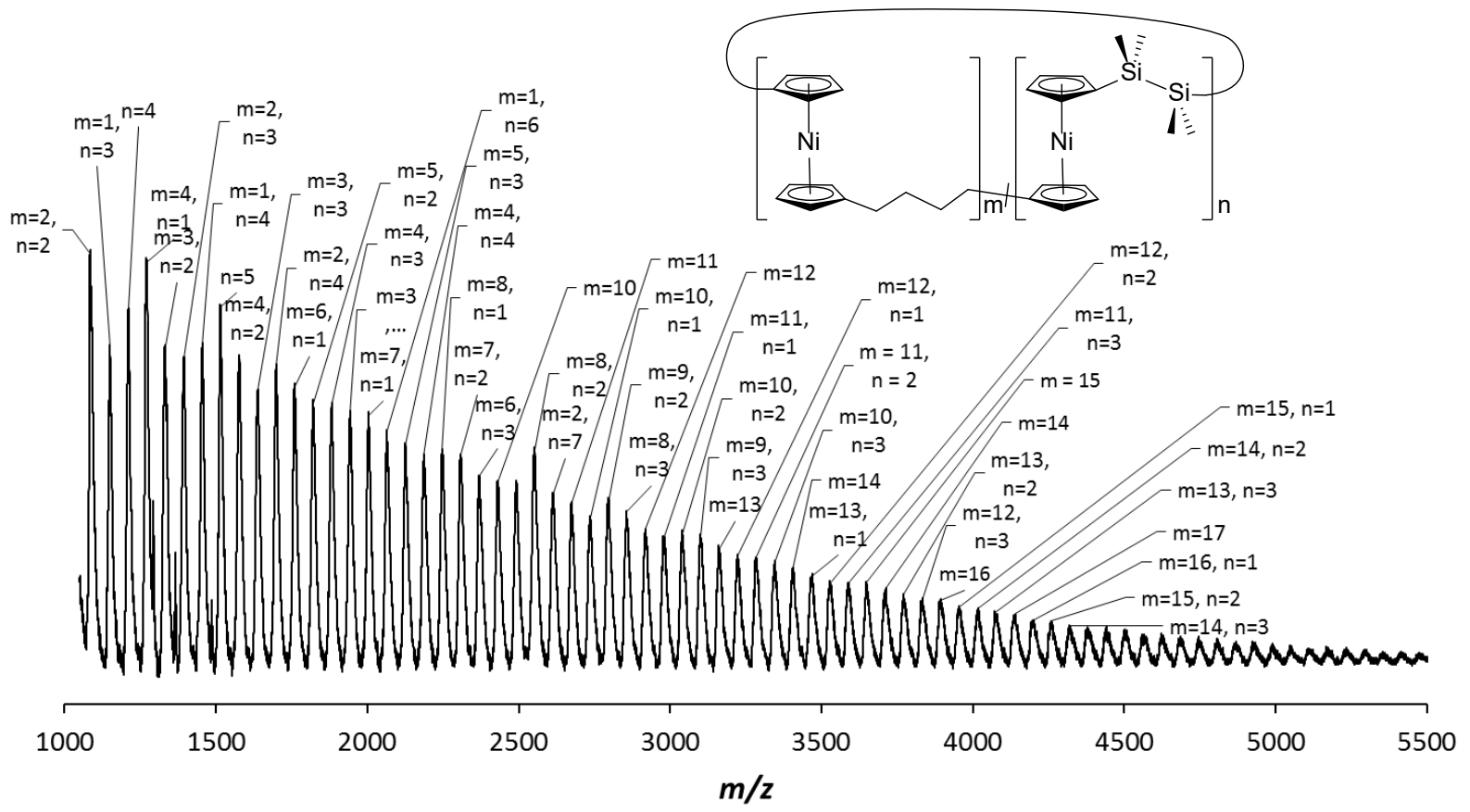

Figure 8. MALDI-TOF mass spectrum of copolymer $\mathbf{1 6} \mathbf{b}$.

\section{iii. Random copolymerisation of 5 and 8}

Finally, the copolymerisation of the $\mathrm{C}_{3}$ and $\mathrm{C}_{4}$-bridged monomers, $\mathbf{5}$ and $\mathbf{8}$, was attempted (Scheme 6). A colour change was observed from dark blue to dark green and a small amount of a light-green precipitate $17_{\text {a }}$ formed. A THF-soluble light-green polymeric product was isolated via precipitation into $n$-hexanes, in $28 \%$ yield. ${ }^{1} \mathrm{H}$ NMR spectroscopy of $\mathbf{1 7} \mathbf{b}$ showed a broad singlet resonance assigned to be overlapping $\mathrm{Cp}$ environments ( $-252 \mathrm{ppm})$; the parent tricarba- and tetracarba-bridged homopolymers display single Cp resonances at -254 and -253 ppm respectively. Two resonances at 174 and 176 ppm were assigned to a $C_{n}$ linker (Figure S14), the former we assign to 7 and the latter 13 with reference to the homopolymer ${ }^{1} \mathrm{H}$ NMR spectra. ${ }^{1} \mathrm{H}$ NMR analysis of $\mathbf{1 3}$ also displayed a peak at $226 \mathrm{ppm}$ assigned to the tetracarbaspacer, but this did not appear in the spectrum for $\mathbf{1} \mathbf{7}_{\mathbf{b}}$. 

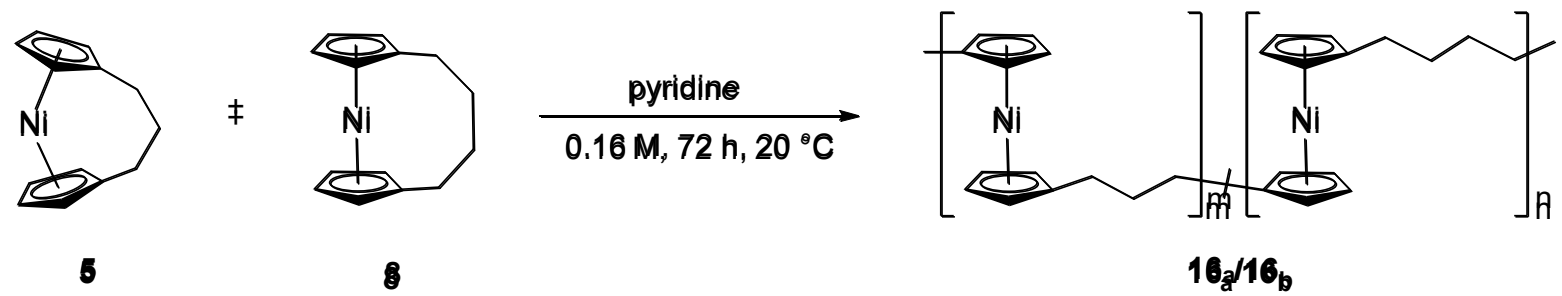

Scheme 6. Co-ROP of $[n]$ nickelocenophanes 5 and 8.

MALDI-TOF of $\mathbf{1 7}_{\mathbf{b}}$ indicated the presence of some co-oligomeric species, with peaks identifiable up to a molecular weight of ca. $3600 \mathrm{~g} \mathrm{~mol}^{-1}$ (Figure S15). In addition, DLS analysis indicated the formation of a polymeric product with a molecular weight of ca. 24000 $\mathrm{g} \mathrm{mol}^{-1}$ and a $\mathrm{DP}_{\mathrm{n}}$ of ca. 103 (relative to calibration with poly(ferrocenyldimethylsilane) in THF, see Figure S16). ${ }^{61,63}$

The WAXS data of the insoluble component $\mathbf{1 7} \mathbf{b}$ was similar to that of both the tricarbaand tetracarba-bridged homopolymers with reflections detected at 8.70, 6.05, 5.34, 5.10, and $3.65 \AA$ (Figure S17).

\section{iv. Attempted random copolymerisation of 5 and [2]cobaltocenophane 18}

To expand the scope of copolymerisations further, we also explored whether the method of synthesising soluble random copolymers could be extended to include cobaltocene repeat units. The copolymerisation of equimolar amounts of 5 and [2] cobaltocenophane $\mathbf{1 8}^{34,64-65}$ was therefore attempted (Scheme 7). No obvious colour change was observed during the reaction from the original red/brown, but a dark grey solid 19a precipitated from the reaction solution which proved insoluble in common organic solvents such as THF, dichloromethane, and benzene. Upon precipitation of the THF-soluble portion of the residue into $n$-hexanes, a grey solid 19b with poor solubility in organic solvents was isolated in very low yield. For comparison, homopolymerisation of the parent $[n]$ nickelocenophane gave green poly(nickelocenylpropylene), whereas the parent $[n]$ cobaltocene yielded a dark purple polymer. $^{34}$ 


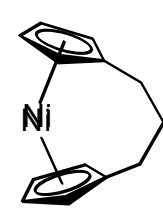

5

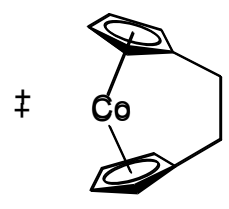

18

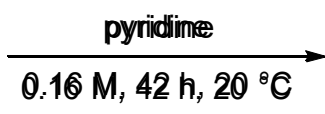

$0.16 \mathrm{M}, 42 \mathrm{~h}, 20^{\circ} \mathrm{C}$

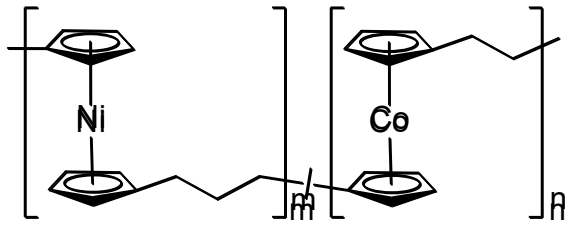

$1 \theta_{\mathrm{a}} / 19_{\mathrm{B}}$

Scheme 7. Co-ROP of $[n]$ nickelocenophane 5 and $[n]$ cobaltocenophane 18.

${ }^{1} \mathrm{H}$ NMR spectroscopy of $19 \mathrm{~b}$ revealed a peak at $-250.5 \mathrm{ppm}$ assigned to the cyclopentadienyl resonances of nickelocene environments, and resonances at -46.1 and $-64.9 \mathrm{ppm}$ attributed to cobaltocene environments (Figure S18). The nickelocene-based cyclopentadienyl resonance appears at the same chemical shift as that observed for homopolymer $\mathbf{6}_{\mathbf{x}} / 7$. As a ${ }^{1} \mathrm{H}$ NMR spectrum was not available for the homopolymer formed from $\mathbf{1 8}$ due to its insolubility, ${ }^{34}$ the assignments made for the cobalt $\mathrm{Cp}$ resonances are given credibility by the MALDI spectrum of the product, which clearly demonstrated the presence of oligomeric species, and as they did not match the resonances of 18 . A peak at 173.7 ppm was attributed to the $\mathrm{CH}_{2}$ groups in carbon linker of the copolymer. ${ }^{1} \mathrm{H}$ NMR spectroscopic analysis of the hexanes soluble supernatant revealed the presence of unreacted $\mathbf{5}$ and 18, alongside a new resonance at $-29 \mathrm{ppm}$ which we assign to the cyclopentadienyl environment of oligomeric cobaltocenophane (higher molecular weight poly(cobaltocenylethylene) is insoluble).

MALDI-TOF mass spectrometry also provided evidence for the formation of copolymer 19 (Figure S20). Peaks up to ca. $1100 \mathrm{~g} \mathrm{~mol}^{-1}$ were recorded for $\mathbf{1 9} \mathrm{b}$, as well as those for oligomeric species derived from both monomers. Analysis by DLS indicated the presence of an oligomeric product $\left(R_{\mathrm{h}}=1.2 \mathrm{~nm}\right)$ with a molecular weight of ca. $2900 \mathrm{~g} \mathrm{~mol}^{-1}$ and a DP of ca. 13 (relative to calibration with poly(ferrocenyldimethylsilane) in THF, see Figure S21). ${ }^{61,66}$

That co-oligomer 19b displays poor organic solvents is perhaps not unexpected. The homopolymerisation of $\mathbf{1 8}$ yields a highly insoluble product which was characterised following oxidation. ${ }^{34}$ It is likely that the difference in the rates of ROP of $\mathbf{5}$ and $\mathbf{1 8}$ leads to a "blocky" 
co-oligomeric product which possesses segments derived from the Ni and Co monomers, where the latter are insoluble in organic solvents.

\section{Magnetic Properties of Polynickelocenes $6 \mathrm{x} / 7,13 \mathrm{a}$, and 14a}

Polynickelocenes are unusual materials with two unpaired electrons on every main chain metal centre. With the preparation of two new polynickelocenes, $13 \mathbf{a}$ and $14_{a}$, we expanded the original study of $\mathbf{6}_{\mathbf{x}} / 7$ by SQUID magnetometry to include these materials and the parent $[n]$ nickelocenophanes. We focussed primarily on the materials that were more compositionally homogeneous in nature, and so the copolymers were excluded from this study.

The magnetic susceptibilities of polynickelocenes $13 \mathbf{a}$ and $14 \mathrm{a}$, as well as $[n]$ nickelocenophanes $\mathbf{8}$ and 12, were studied in the solid state using SQUID magnetometry at an applied magnetic field of 0.1 Tesla in the temperature range $6-300 \mathrm{~K}$. The insoluble fractions of the tetracarba- and disila-bridged polynickelocenes were studied due to their high yields compared to the soluble fractions. For each complex, the observed magnetic susceptibility per mole of nickel $\left(\chi_{\mathrm{m}}\right)$ at each temperature was almost identical for zero-field cooled (ZFC) and field cooled (FC) measurements (Figures S22 and S23), hence only ZFC data are shown. Furthermore, no evidence was found for magnetic hysteresis at 5 and $300 \mathrm{~K}$ (Figures S24 and S25).

The plot of $\chi_{\mathrm{m}}^{-1}$ vs $T$ (Figures $\mathrm{S} 26 \mathrm{~b}-\mathrm{S} 30 \mathrm{~b}$ ) is linear in the region $50-300 \mathrm{~K}$ for all complexes studied. Hence, the observed susceptibility data were fitted to the Curie-Weiss law, where $C$ is the Curie constant and $\Theta$ is the Weiss temperature, with the addition of a small term for a temperature-independent paramagnetic contribution, $\chi_{\mathrm{TIP}}$ (Equation 1).

$$
\chi_{m}=\frac{C}{T-\Theta}+\chi_{T I P}
$$

\section{Equation 1}

The parameters obtained from the least-squares Curie-Weiss fits for $\mathbf{1 3}_{\mathbf{a}}, \mathbf{1 4} \mathbf{a}, \mathbf{8}$ and $\mathbf{1 2}$, are collected in Table 1, together with data for the tricarba[3]nickelocenophane 5, and those 
previously reported for poly(nickelocenylpropylene), $6 \mathbf{x} / 7 .{ }^{49}$

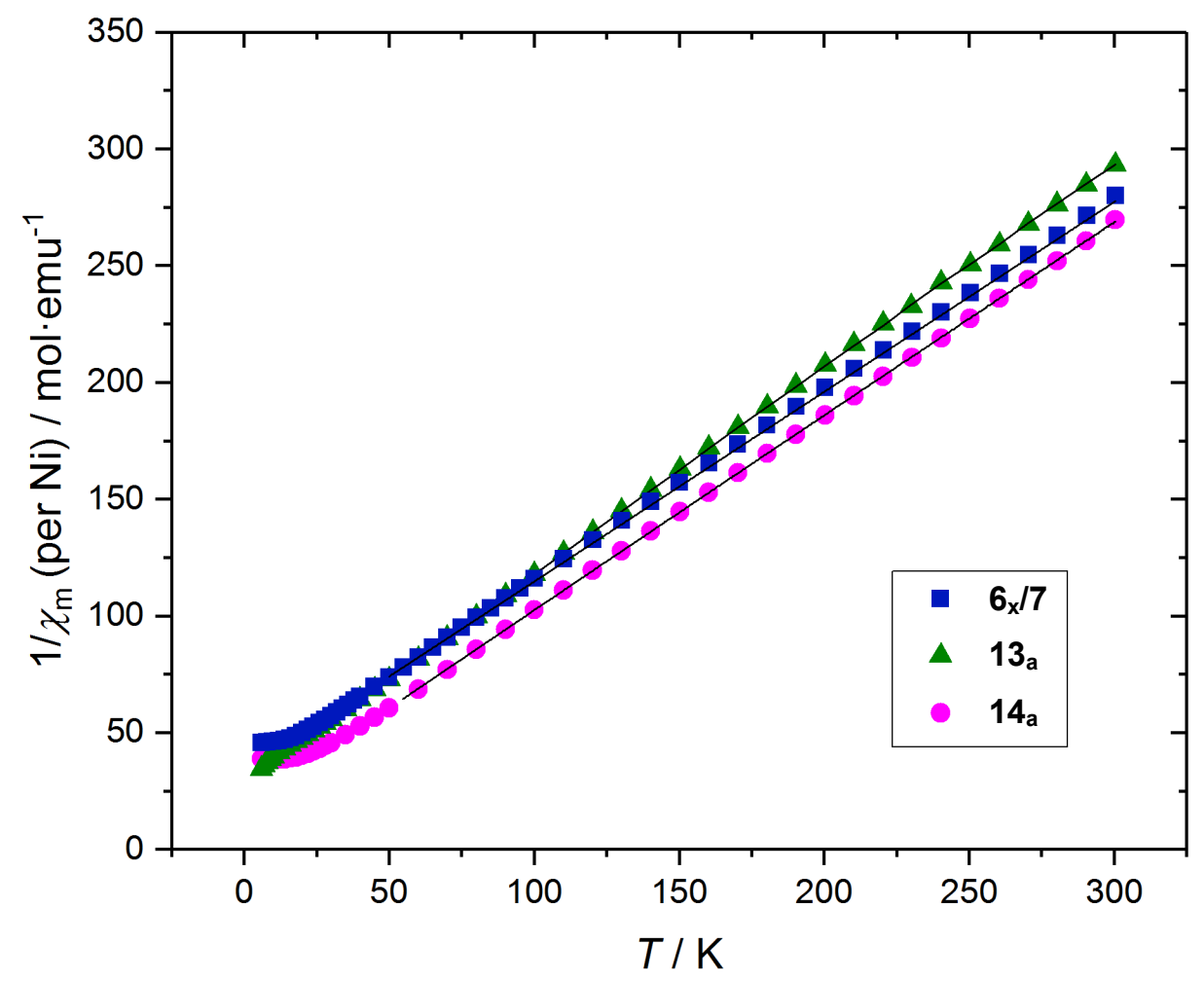

Figure 9. Temperature dependence of inverse magnetic susceptibility per nickel $\left(1 / \chi_{\mathrm{m}}\right)$ for poly(nickelocenylpropylene), 6x/7, poly(nickelocenylbutylene), 13a, and poly(nickelocenyltetramethyldisilane), 14a. The black lines represent the best fits of the data to Equation 1 in the Curie-Weiss regime $(50-300 \mathrm{~K})$.

The $\mu_{\text {eff }}$ values for 13a and 14a (2.94 and $3.01 \mu_{\mathrm{B}}$ respectively) agree well with the value previously reported for $\mathbf{6}_{\mathrm{x}} / \mathbf{7}\left(2.94 \mu_{\mathrm{B}}\right)$ in the Curie-Weiss regime. ${ }^{49}$ These are slightly greater than $\mu_{\mathrm{eff}}$ values reported for monomeric nickelocenes $\left(2.88-2.92 \mu_{\mathrm{B}}\right) .{ }^{50,67-69}$

In a Curie-Weiss model, interactions between magnetic centres are considered in a mean field approach, parameterised by the Weiss temperature $(\Theta)$. All complexes studied showed negative values of $\Theta$, characteristic of antiferromagnetic spin-spin interactions. The magnitude of $\Theta$ is significantly larger for polynickelocenes $\mathbf{6} \mathbf{x} / 7, \mathbf{1 3}_{\mathbf{a}}$ and $\mathbf{1 4} \mathbf{a}$ (range -37.1 to $-21.3 \mathrm{~K}$ ), as 
compared with nickelocenophanes $\mathbf{5 , 8}$ and $\mathbf{1 2}$ (range -5.0 to $-3.4 \mathrm{~K}$ ), which suggests greater antiferromagnetic coupling in the polymeric species. The antiferromagnetic ordering found in 5, 8 and 12 can be attributed to intermolecular interactions, and, assuming these are same order of magnitude for mononuclear and polynuclear nickelocenes, we postulate that the greater antiferromagnetic coupling in the $6 \mathbf{x} / 7,13 \mathrm{a}$, and $14 \mathrm{a}$ is caused by a through-bond coupling via the main chain spacers. This is in contrast to magnetic behaviour for the heteroleptic polyvanadocene $\left[\mathrm{V}\left(\eta^{5}-\mathrm{C}_{5} \mathrm{H}_{4}\right)\left(\eta^{7}-\mathrm{C}_{7} \mathrm{H}_{6}\right) \mathrm{Sn}^{t} \mathrm{Bu}_{2}\right]_{n}(n \approx 99 / 204)$ reported by Braunschweig et al., which shows a smaller negative $\Theta$ value than the corresponding mononuclear vanadocenophane, $\left[\mathrm{V}\left(\eta^{5}-\mathrm{C}_{5} \mathrm{H}_{4}\right)\left(\eta^{7}-\mathrm{C}_{7} \mathrm{H}_{6}\right) \mathrm{Sn}^{t} \mathrm{Bu}_{2}\right]{ }^{70}$

Comparing the Curie-Weiss $\Theta$ values within the series of polynickelocenes reveals that the strength of antiferromagnetic interaction decreases in the order of $\mathbf{6}_{\mathbf{x}} / \mathbf{7}>1 \mathbf{1 3}_{\mathrm{a}},>1 \mathbf{1 4}_{\mathrm{a}}$, suggesting that the all-carbon bridges in $6 \mathbf{x} / 7$ and 13 a better mediate spin-spin interactions compared to the disilyl-bridge in 14a. However, we can only draw tentative conclusions based on Curie-Weiss $\Theta$ values alone. Differential Scanning Calorimetry (DSC) allowed the cautious assignation of the small melt transitions of $\mathbf{1 3} \mathbf{a}$ and $14 \mathbf{a}$ close to $100{ }^{\circ} \mathrm{C}$ (Figures S7 and S8). This is consistent with the WAXS data acquired at $295 \mathrm{~K}$, which shows several peaks characteristic of the presence of a significant degree of crystallinity. Below $300 \mathrm{~K}$ polynickelocene $\mathrm{Cp}$ rings would likely display little molecular motion; ${ }^{71}$ thus, any difference between the polymers could be attributed to the bridging moieties. Reports have described greater motion in silicon-based materials at low temperature due to the inherent flexibility and lower chain torsion manifested in the longer $\mathrm{C}-\mathrm{Si}$ and $\mathrm{Si}-\mathrm{Si}$ bonds compared to $\mathrm{C}-\mathrm{C}$ bonds. ${ }^{72-}$ 74 This may contribute to the lower antiferromagnetic spin-spin interactions in the disilylbridged polynickelocene $14_{a}$ compared to those in the carbon-bridged $\mathbf{6}_{\mathrm{x}} / \mathbf{7}$ and $\mathbf{1 3} \mathrm{a}$.

The magnetic susceptibility of the mononuclear and polynuclear nickelocenes in this study deviate significantly from simple paramagnetic behaviour below $50 \mathrm{~K}$. Similar low 
temperature magnetic behaviour has been observed in nickelocene by Prins et al., who attributed it to the large zero-field spitting $(D)$ in the triplet ground state. ${ }^{69}$ Therefore, the SQUID data for $5,8,12,6 \times / 7,13 a$, and $14 a$ were simulated using a fitting procedure to the spin Hamiltonian for the Zeeman splitting (Equation 2). ${ }^{75}$

$$
\widehat{H}=g \mu_{\mathrm{B}} \vec{B} \cdot \vec{S}
$$

Equation 2

where

$$
\begin{aligned}
\widehat{H}_{Z e e} & =g \mu_{\mathrm{B}} \vec{B} \cdot \vec{S} \\
\widehat{H}_{Z F S} & =D\left[S^{2}-1 / 3 S(S+1)\right]
\end{aligned}
$$

\section{Equation 3}

Equation 4

All complexes were treated as individual $S=1$ units, using the variables $g, \Theta, \chi_{\mathrm{TIP}}$ and $D$ across the entire temperature range, $6-300 \mathrm{~K}$. The best fit to the $\chi_{\mathrm{m}} T$ data are shown in Figure 10 , and the simulated parameters are listed in Table 1. The magnitude of the zero-field splitting simulated for $[n]$ nickelocenophanes $\mathbf{5 ,}, \mathbf{8}$, and $\mathbf{1 2}\left(\right.$ range $\left.32.0-32.3 \mathrm{~cm}^{-1}\right)$, is of a similar order to those previously reported for nickelocene. ${ }^{69,76-78}$ The $D$ values for $\mathbf{6}_{\mathbf{x}} / 7, \mathbf{1 3} \mathbf{a}$, and $1 \mathbf{1 4}_{\mathbf{a}}$ (range $42.0-57.6 \mathrm{~cm}^{-1}$ ) are significantly larger than those of the parent $[n]$ nickelocenophanes, suggesting a larger zero-field splitting in the polymeric species. The Weiss temperatures $(\Theta)$ obtained from these simulations have significantly larger negative values for carbon-bridged polynickelocenes $\mathbf{6}_{\mathbf{x}} / \mathbf{7}$ and $13 \mathbf{a}(-23.5$ and $-25.0 \mathrm{~K}$ respectively) compared with disilyl-bridged polynickelocene 14a $(-7.0 \mathrm{~K})$, and are almost negligible for nickelocenophanes $\mathbf{5}, \mathbf{8}$ and 12.

Solid state samples of $\mathbf{1 3}_{\mathbf{a}}$ and $\mathbf{1 4} \mathbf{a}$ did not show an X-band EPR spectrum at $85 \mathrm{~K}$. Nussbaum et al. also failed in measuring an EPR signal of nickelocene, which was attributed to a strong zero-field splitting in the triplet ground state. ${ }^{79}$ 


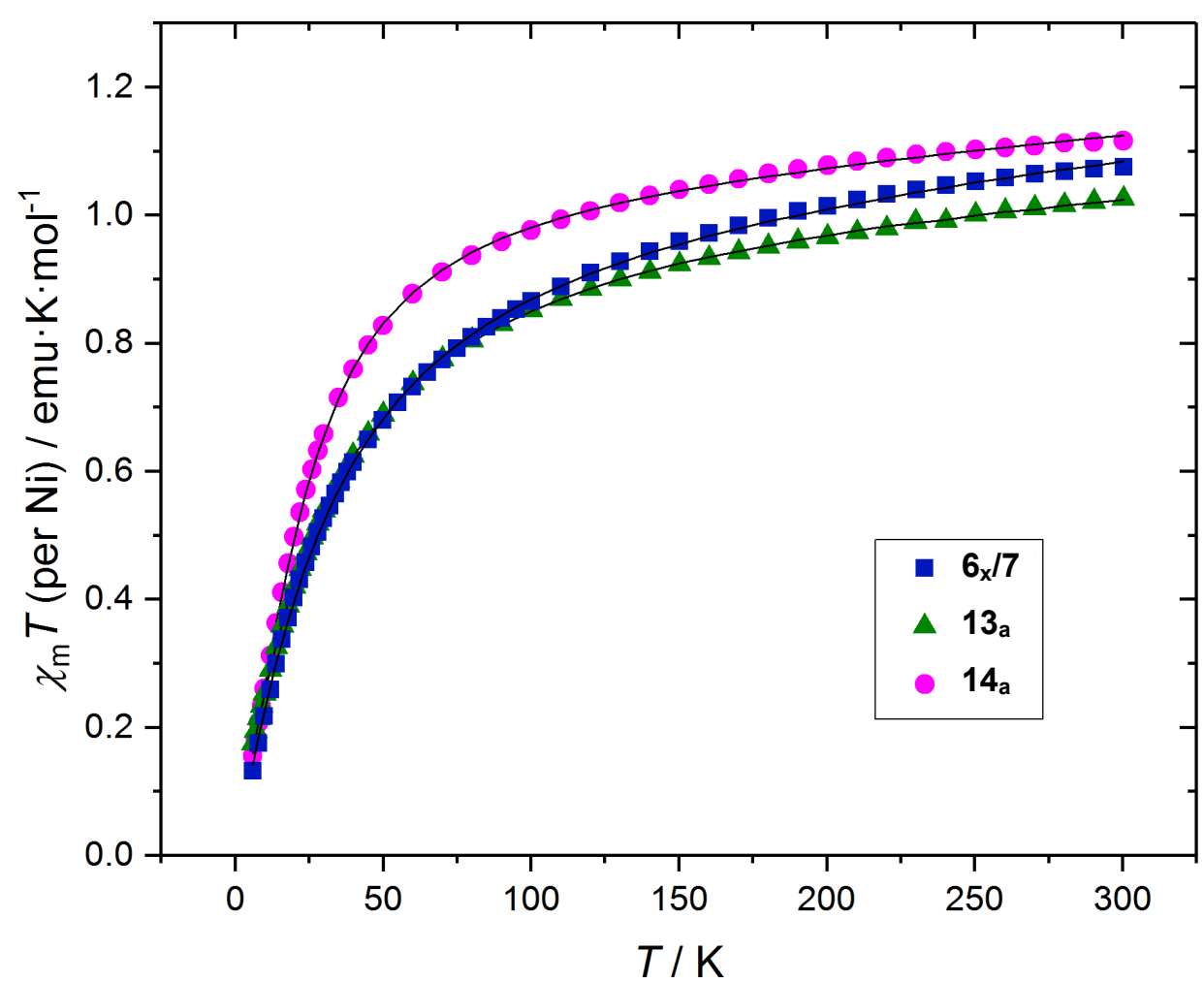

Figure 10. Temperature dependence of the observed $\chi_{\mathrm{m}} T$ product (per Ni) for poly(nickelocenylpropylene), 6x/7, poly(nickelocenylbutylene), 13a, and poly(nickelocenyltetramethyldisilane), 14a. The black lines represent the simulated data in the range $6-300 \mathrm{~K}$.

Table 1. Parameters derived from fitting of the variable temperature magnetic susceptibility data to the Curie-Weiss law (Equation 1) or the spin Hamiltonian (Equation 2).

\begin{tabular}{|c|c|c|c|c|c|c|c|}
\hline & \multicolumn{3}{|c|}{ Curie-Weiss fit $(50-300 \mathrm{~K})$} & \multicolumn{4}{|c|}{ JulX simulation (6 - 300 K) } \\
\hline & $\begin{array}{l}\mu_{\text {eff }} \\
\left(\mu_{\mathrm{B}}\right)\end{array}$ & $\Theta(\mathbf{K})$ & $\begin{array}{l}\chi \mathrm{TIP} / 10^{6} \\
(\mathrm{emu} \\
\left.\mathrm{mol}^{-1}\right)\end{array}$ & $\mu_{\text {eff }}\left(\mu_{\mathrm{B}}\right)$ & $\boldsymbol{\Theta}(\mathbf{K})$ & $\begin{array}{l}\chi_{\mathrm{TIP}} / 10^{6} \\
\left(\mathrm{emu} \mathrm{mol}{ }^{-1}\right)\end{array}$ & $D\left(\mathrm{~cm}^{-1}\right)$ \\
\hline $\mathbf{6}_{\mathbf{x}} / 7^{49}$ & 2.94 & -37.1 & 168 & 2.90 & -23.5 & 365.8 & 57.6 \\
\hline $13 \mathbf{a}$ & 2.94 & -29.2 & 109 & 2.91 & -25.0 & 168.6 & 42.0 \\
\hline
\end{tabular}




\begin{tabular}{l|lll|llll}
$\mathbf{1 4}$ & 3.01 & -21.3 & 53.1 & 2.89 & -7.0 & 352 & 55.4 \\
\hline $\mathbf{5}$ & 2.83 & -4.2 & 0 & 2.82 & -0.8 & 0 & 32.2 \\
$\mathbf{8}$ & 2.90 & -5.0 & 0 & 2.88 & -0.7 & 49.0 & 32.3 \\
$\mathbf{1 2}$ & 2.97 & -3.4 & 0 & 2.92 & 0.6 & 66.4 & 32.0 \\
\hline
\end{tabular}

\section{Summary}

Due to an exciting report on the reversible nature of the polymerisation of moderately strained [3]nickelocenophane 5 to give polynickelocene $\mathbf{6}_{\mathbf{x}} / 7,{ }^{51}$ we aimed to expand the field and synthesise further polynickelocenes. Primarily, the ROP of untilted $\left[\mathrm{Ni}\left(\eta^{5}-\mathrm{C}_{5} \mathrm{H}_{4}\right)_{2}\left(\mathrm{CH}_{2}\right)_{4}\right](\mathbf{8})$ was performed in pyridine to yield predominantly insoluble poly(nickelocenylbutylene) (13a); this unusual result represents the first example of $[n]$ metallocenophane ROP in the absence of $\mathrm{Cp}$ ring tilt. ROP of moderately strained $\left[\mathrm{Ni}\left(\eta^{5}-\mathrm{C}_{5} \mathrm{H}_{4}\right)_{2}\left(\mathrm{SiMe}_{2}\right)_{2}\right]$ (12) also yielded predominantly insoluble polymeric products, although polymeric material with increased solubility was synthesised by copolymerisation $[n]$ metallocenophane monomers. Additionally, the ROPs of $\mathbf{8}$ and $\mathbf{1 2}$ were found to be reversible at elevated temperatures. As polynickelocenes 6x $/ 7,13 \mathrm{a}$, and $14 \mathrm{a}$ contain two unpaired electrons per nickelocene unit, we performed SQUID magnetometry measurements that indicated that they act as simple paramagnets at higher temperatures and display significant antiferromagnetic coupling that occurs primarily in a through-bond manner. However, at low temperatures these polynickelocenes deviate from the Curie-Weiss due to substantial zero-field splitting. Further work will focus on determining why 8 undergoes ROP to give 13, despite its lack of ring strain. Additionally, the redox properties of the nickelocenophanes and polynickelocenes explored here are of interest.

\section{References}

1. Xiang, J.; Ho, C. L.; Wong, W. Y., Polym. Chem. 2015, 6, 6905-6930. 
2. Whittell, G. R.; Hager, M. D.; Schubert, U. S.; Manners, I., Nat. Mater. 2011, 10, 176188.

3. Yan, Y.; Zhang, J.; Ren, L.; Tang, C., Chem. Soc. Rev. 2016, 5232-5263.

4. Collot, J.; Gradinaru, J.; Humbert, N.; Skander, M.; Zocchi, A.; Ward, T. R., J. Am. Chem. Soc. 2003, 125, 9030-9031.

5. Zhang, J. Y.; Chen, Y. P.; Miller, K. P.; Ganewatta, M. S.; Bam, M.; Yan, Y.; Nagarkatti, M.; Decho, A. W.; Tang, C. B., J. Am. Chem. Soc. 2014, 136, 4873-4876.

6. Tse, C. W.; Man, K. Y. K.; Cheng, K. W.; Mak, C. S. K.; Chan, W. K.; Yip, C. T.; Liu, Z. T.; Djurisic, A. B., Chem. Eur. J. 2007, 13, 328-335.

7. $\quad$ Wong, W.-Y.; Ho, C.-L., Accounts Chem. Res. 2010, 43, 1246-1256.

8. $\quad$ Choi, T. L.; Lee, K. H.; Joo, W. J.; Lee, S.; Lee, T. W.; Chae, M. Y., J. Am. Chem. Soc. 2007, 129, 9842-9843.

9. $\quad$ Wu, F.-I.; Yang, X.-H.; Neher, D.; Dodda, R.; Tseng, Y.-H.; Shu, C.-F., Adv. Funct. Mater. 2007, 17, 1085-1092.

10. Stanley, J. M.; Holliday, B. J., Coord. Chem. Rev. 2012, 256, 1520-1530.

11. Burnworth, M.; Tang, L. M.; Kumpfer, J. R.; Duncan, A. J.; Beyer, F. L.; Fiore, G. L.; Rowan, S. J.; Weder, C., Nature 2011, 472, 334-337.

12. $\quad$ Bode, S.; Zedler, L.; Schacher, F. H.; Dietzek, B.; Schmitt, M.; Popp, J.; Hager, M. D.; Schubert, U. S., Adv. Mater. 2013, 25, 1634-1638.

13. Kim, H. J.; Lee, J. H.; Lee, M., Angew. Chem. Int. Ed. 2005, 44, 5810-5814.

14. MacLachlan, M. J.; Ginzburg, M.; Coombs, N.; Raju, N. P.; Greedan, J. E.; Ozin, G. A.; Manners, I., J. Am. Chem. Soc. 2000, 122, 3878-3891.

15. Ginzburg, M.; MacLachlan, M. J.; Yang, S. M.; Coombs, N.; Coyle, T. W.; Raju, N. P.; Greedan, J. E.; Herber, R. H.; Ozin, G. A.; Manners, I., J. Am. Chem. Soc. 2002, 124, $2625-$ 2639.

16. Ruttiger, C.; Pfeifer, V.; Rittscher, V.; Stock, D.; Scheid, D.; Vowinkel, S.; Roth, F.; Didzoleit, H.; Stuhn, B.; Elbert, J.; Ionescu, E.; Gallei, M., Polym. Chem. 2016, 7, 1129-1137. 17. Zhang, J.; Yan, Y.; Chance, M. W.; Chen, J.; Hayat, J.; Ma, S.; Tang, C., Angew. Chem. Int. Ed. 2013, 52, 13387-13391.

18. Rider, D. A.; Liu, K.; Eloi, J. C.; Vanderark, L.; Yang, L.; Wang, J. Y.; Grozea, D.; Lu, Z. H.; Russell, T. P.; Manners, I., Acs Nano 2008, 2, 263-270.

19. Korczagin, I.; Lammertink, R. G. H.; Hempenius, M. A.; Golze, S.; Vancso, G. J., Adv. Polym. Sci. 2006, 200, 91-117.

20. Wang, Y. L.; Salmon, L.; Ruiz, J.; Astruc, D., Nat. Commun. 2014, 5, 1-12.

21. Yang, M. J.; Zhang, L. J.; Lei, Z. Q.; Ye, P. X.; Si, J. H.; Yang, Q. G.; Wang, Y. G., J. Appl. Polym. Sci. 1998, 70, 1165-1172.

22. Ding, X. S.; Guo, J.; Feng, X. A.; Honsho, Y.; Guo, J. D.; Seki, S.; Maitarad, P.; Saeki, A.; Nagase, S.; Jiang, D. L., Angew. Chem. Int. Ed. 2011, 50, 1289-1293.

23. McDonald, R.; Sturge, K. C.; Hunter, A. D.; Shilliday, L., Organometallics 1992, 11, 893-900.

24. Sturge, K. C.; Hunter, A. D.; Mcdonald, R.; Santarsiero, B. D., Organometallics 1992, $11,3056-3062$.

25. Macdonald, P. M.; Hunter, A. D.; Lesley, G.; Li, J., Solid State Nuclear Magnetic Resonance 1993, 2, 47-55.

26. Paquette, J. A.; Sauve, E. R.; Gilroy, J. B., Macromol. Rapid Commun. 2015, 36, 621626.

27. Dai, Y. J.; Katz, T. J., J. Org. Chem. 1997, 62, 1274-1285.

28. Dai, Y. J.; Katz, T. J.; Nichols, D. A., Angew. Chem. Int. Ed. 1996, 35, 2109-2111.

29. Rosenblum, M.; Nugent, H. M.; Jang, K. S.; Labes, M. M.; Cahalane, W.; Klemarczyk, P.; Reiff, W. M., Macromolecules 1995, 28, 6330-6342. 
30. Nugent, H. M.; Rosenblum, M.; Klemarczyk, P., J. Am. Chem. Soc. 1993, 115, 38483849.

31. Mugemana, C.; Gohy, J. F.; Fustin, C. A., Langmuir 2012, 28, 3018-3023.

32. Paquette, J. A.; Rabiee Kenaree, A.; Gilroy, J. B., Polym. Chem. 2017, 8, 2164-2172.

33. Hailes, R. L. N.; Oliver, A. M.; Gwyther, J.; Whittell, G. R.; Manners, I., Chem. Soc. Rev. 2016, 45, 5358-5407.

34. Mayer, U. F. J.; Gilroy, J. B.; O'Hare, D.; Manners, I., J. Am. Chem. Soc. 2009, 131, 10382-10383.

35. Bagh, B.; Gilroy, J. B.; Staubitz, A.; Müller, J., J. Am. Chem. Soc. 2010, 132, 17941795.

36. Braunschweig, H.; Adams, C. J.; Kupfer, T.; Manners, I.; Richardson, R. M.; Whittell, G. R., Angew. Chem. Int. Ed. 2008, 47, 3826-3829.

37. Espada, L.; Pannell, K. H.; Papkov, V.; Leites, L.; Bukalov, S.; Suzdalev, I.; Tanaka, M.; Hayashi, T., Organometallics 2002, 21, 3758-3761.

38. Ma, Y.; Dong, W.-F.; Hempenius, M. A.; Möhwald, H.; Vancso, G. J., Nat. Mater. 2006, 5, 724-729.

39. Hempenius, M. A.; Cirmi, C.; Song, J.; Vancso, G. J., Macromolecules 2009, 42, 23242326.

40. MacLachlan, M. J.; Ginzburg, M.; Coombs, N.; Coyle, T. W.; Raju, N. P.; Greedan, J. E.; Ozin, G. A.; Manners, I., Science 2000, 287, 1460-1463.

41. Lastella, S.; Mallick, G.; Woo, R.; Karna, S. P.; Rider, D. A.; Manners, I.; Jung, Y. J.; Ryu, C. Y.; Ajayan, P. M., J. Appl. Phys. 2006, 99, 024302.

42. Lu, J.; Chamberlin, D.; Rider, D. A.; Liu, M.; Manners, I.; Russell, T. P., Nanotechnology 2006, 17, 5792-5797.

43. Gädt, T.; Ieong, N. S.; Cambridge, G.; Winnik, M. A.; Manners, I., Nat. Mater. 2009, $8,144-150$.

44. Wang, X.; Guerin, G.; Wang, H.; Wang, Y.; Manners, I.; Winnik, M. A., Science 2007, 317, 644-647.

45. Long, N. J., In Metallocenes: An introduction to sandwich complexes, 1st ed.; WileyBlackwell: 1998.

46. Finckh, W.; Tang, B. Z.; Foucher, D. A.; Zamble, D. B.; Ziembinski, R.; Lough, A.; Manners, I., Organometallics 1993, 12, 823-829.

47. Braunschweig, H.; Breher, F.; Kaupp, M.; Gross, M.; Kupfer, T.; Nied, D.; Radacki, K.; Schinzel, S., Organometallics 2008, 27, 6427-6433.

48. Braunschweig, H.; Gross, M.; Radacki, K., Organometallics 2007, 26, 6688-6690.

49. Baljak, S.; Russell, A. D.; Binding, S. C.; Haddow, M. F.; O'Hare, D.; Manners, I., J. Am. Chem. Soc. 2014, 136, 5864-5867.

50. Trtica, S.; Meyer, E.; Prosenc, M. H.; Heck, J.; Bohnert, T.; Gorlitz, D., Eur. J. Inorg. Chem. 2012, 4486-4493.

51. Musgrave, R. A.; Russell, A. D.; Hayward, D. W.; Whittell, G. R.; Lawrence, P. G.; Gates, P. J.; Green, J. C.; Manners, I., Nat. Chem. 2017, 9, 743-750.

52. Tel'noi, V. I.; Rabinovich, I. B., Usp Khim+ 1977, 46, 1337-1367.

53. Tanabe, M.; Vandermeulen, G. W. M.; Chan, W. Y.; Cyr, P. W.; Vanderark, L.; Rider, D. A.; Manners, I., Nat. Mater. 2006, 5, 467-470.

54. Buchowicz, W.; Jerzykiewicz, L. B.; Krasinska, A.; Losi, S.; Pietrzykowski, A.; Zanello, P., Organometallics 2006, 25, 5076-5082.

55. Herbert, D. E.; Mayer, U. F. J.; Manners, I., Angew. Chem. Int. Ed. 2007, 46, 50605081.

56. Musgrave, R. A.; Russell, A. D.; Manners, I., Organometallics 2013, 32, 5654-5667. 
57. Musgrave, R. A.; Russell, A. D.; Whittell, G. R.; Haddow, M. F.; Manners, I., Organometallics 2015, 34, 897-907.

58. Foucher, D. A.; Tang, B. Z.; Manners, I., J. Am. Chem. Soc. 1992, 114, 6246-6248.

59. Hudson, R. D. A.; Foxman, B. M.; Rosenblum, M., Organometallics 1999, 18, 40984106.

60. The $\mathrm{DP}_{\mathrm{n}}$ in this case was calculated using an average molecular weight for the monomer units derived from $5\left(228.9 \mathrm{~g} \mathrm{~mol}^{-1}\right)$ and $\mathbf{1 2}\left(303.2 \mathrm{~g} \mathrm{~mol}^{-1}\right)$, and assuming a 1:1 ratio of incorportion of these units into copolymer 15.

61. Massey, J. A.; Kulbaba, K.; Winnik, M. A.; Manners, I., Journal of Polymer Science Part B: Polymer Physics 2000, 38, 3032-3041.

62. The $\mathrm{DP}_{\mathrm{n}}$ in this case was calculated using an average molecular weight for the monomer units derived from $8\left(243.0 \mathrm{~g} \mathrm{~mol}^{-1}\right)$ and $12\left(303.2 \mathrm{~g} \mathrm{~mol}^{-1}\right)$, and assuming a 1:1 ratio of encorportion of these units into polymer $\mathbf{1 6}$.

63. The $\mathrm{DP}_{\mathrm{n}}$ in this case was calculated using an average molecular weight for the monomer units derived from $5\left(228.9 \mathrm{~g} \mathrm{~mol}^{-1}\right)$ and $8\left(243.0 \mathrm{~g} \mathrm{~mol}^{-1}\right)$, and assuming a 1:1 ratio of encorportion of these units into polymer 17.

64. Mayer, U. F. J.; Charmant, J. P. H.; Rae, J.; Manners, I., Organometallics 2008, 27 , 1524-1533.

65. Gilroy, J. B.; Patra, S. K.; Mitchels, J. M.; Winnik, M. A.; Manners, I., Angew. Chem. Int. Ed. 2011, 50, 5851-5855.

66. The $\mathrm{DP}_{\mathrm{n}}$ in this case was calculated using an average molecular weight for the monomer units derived from $5\left(228.9 \mathrm{~g} \mathrm{~mol}^{-1}\right)$ and $\mathbf{1 8}\left(215.1 \mathrm{~g} \mathrm{~mol}^{-1}\right)$, and assuming a 1:1 ratio of encorportion of these units into polymer 19.

67. Von E. O. Fischer; Jira, R., Zeitschrift Fur Naturforschung 1953, 8 b, 217-219.

68. Wilkinson, G.; Pauson, P. L.; Cotton, F. A., J. Am. Chem. Soc. 1954, 76, 1970-1974.

69. Prins, R.; Van Voorst, J. D. W.; Schinkel, C. J., Chem. Phys. Lett. 1967, 1, 54-55.

70. Braunschweig, H.; Damme, A.; Demeshko, S.; Dück, K.; Kramer, T.; Krummenacher, I.; Meyer, F.; Radacki, K.; Stellwag-Konertz, S.; Whittell, G. R., J. Am. Chem. Soc. 2015, 137, 1492-1500.

71. Kulbaba, K.; Manners, I.; Macdonald, P. M., Macromolecules 2002, 35, 10014-10025.

72. $\quad$ Spiess, H. W., Colloid and Polymer Science 1983, 261, 193-209.

73. Hentschel, D.; Sillescu, H.; Spiess, H. W., Die Makromolekulare Chemie 1979, 180, 241-249.

74. Interrante, L. V.; Liu, Q.; Rushkin, I.; Shen, Q., J. Organomet. Chem. 1996, 521, 1-10.

75. Simulations of the experimental magnetic data were carried out using the JulX program (version 1.5), w. b. D. E. B. M.-P.-I. f. B. C., Mühlheim an der Ruhr, Germany).

76. A. V. Zvarykina; E. V. Karimov; Yu, S.; E. V. Leonova; Lyubovskii, R. B., Sov. Phys.Solid State 1970, 12, 385.

77. Oswald, N. Ph.D. Thesis No. 5922. ETH Zürich, Switzerland, 1977.

78. Baltzer, P.; Furrer, A.; Hulliger, J.; Stebler, A., Inorg. Chem. 1988, 27, 1543-1548.

79. M. Nussbaum; Voitlander, J. Z., Naturforsch., A: Astrophys., Phys., Phys. Chem. 1965, $20 \mathrm{~A}, 1417$. 